\title{
Use of fresh versus frozen or blast-frozen grapes for small-scale fermentation
}

\author{
This article was published in the following Dove Press journal: \\ International Journal of Wine Research \\ 18 October 2011 \\ Number of times this article has been viewed
}

\section{Frank Schmid \\ Vladimir Jiranek \\ School of Agriculture, Food and Wine, The University of Adelaide; and Wine Innovation Cluster, The Waite Campus, Glen Osmond, South Australia, Australia}

Background: This paper firstly examines the validity of using laboratory-scale fermentations as a means of correlating winemaking outcomes with larger industrial scale fermentations. Secondly, conventional and blast-freezing of whole bunches were investigated for their relative suitability as methods of preservation as determined by the nature of the resulting wines.

Methods: Red must fermentations were compared at the laboratory $80 \mathrm{~kg}$ scale, and the more industrially representative $500 \mathrm{~kg}$ pilot scale. Fermentation profiles and duration for both scales were found to be very similar. Whole bunches were either slow/conventionally frozen $\left(-20^{\circ} \mathrm{C}\right)$, or quickly/blast-frozen $\left(-25^{\circ} \mathrm{C}\right)$.

Results: Wines made from frozen grapes compared well with the wine made from the fresh must. Color and chemical analyses of the wines revealed few differences. A duo-trio sensory evaluation showed that wine from blast-frozen grapes was more similar to the fresh wines than wines from conventional frozen grapes.

Conclusion: The findings of this research suggest that whole-bunch blast-freezing of grapes is preferable to conventional freezing.

Keywords: wine color, research winemaking, frozen grapes

\section{Introduction}

The proof of the benefits of winemaking or viticultural treatments is generally obtained through comparison of the resulting wines. However, in making these test wines as a proof-of-concept, financial and practical considerations often dictate that small-lot fermentations are carried out before the commitment to assessments on a larger or commercial scale. The approach to such scaled-down trials can be highly variable, and the accuracy with which they model the industrial situation is rarely defined. A further limitation of oenological research, particularly using red grapes, is that any winemaking is predominantly restricted to the vintage period when grapes are available.

This project explored the possibility of using frozen whole grapes to take full advantage of research equipment outside of vintage. Some studies have investigated quality changes of berries/must after frozen storage and have shown few adverse effects. ${ }^{1,2}$ Our recent study ${ }^{3}$ showed promising findings comparing the use of fresh and frozen musts, and suggested that frozen must provided a reasonable approximation of fresh grapes. Of course, disadvantages of storing musts as opposed to grapes are that significant processing is require before refrigeration, must have to be directly aliquoted into the desired fermentation volume because of the difficulty in maintaining juice to skin ratios of subaliquots after the fact, and rupture of grapes presents increased opportunities for microbial and oxidative spoilage. Freezing of intact grapes is 
therefore preferable. Traditional freezing (ie, $-20^{\circ} \mathrm{C}$ ) of kilogram amounts of grapes or must requires hours to days to be completed, depending on the volume. Such a slow rate of freezing is undesirable, because it provides opportunity for continued change in berry composition. ${ }^{4}$ Blast-freezing appeared to be a superior option, but no indepth work had been reported. Therefore, we sought to expand and extend our earlier work ${ }^{3}$ by comparing the fermentation and wine characteristics of blast-frozen and "slow" frozen grapes with fresh grapes. The specific aims of the project were to determine the extent of agreement between $80 \mathrm{~kg}$ (about $100 \mathrm{~L}$ ) and $500 \mathrm{~kg}$ (about $700 \mathrm{~L}$ ) fermentations with regard to winemaking outcome and to evaluate the acceptability of using "slow" frozen versus blast-frozen whole bunches compared with fresh bunches.

\section{Materials and methods Processing of grapes}

Merlot grapes (chosen due to availability) were hand-harvested in early April 2007 from a vineyard near Woodside, Adelaide

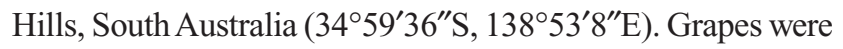
split into three lots on a randomized, bunch-by-bunch basis. One lot was used fresh $(3 \times 500 \mathrm{~kg}$ and $3 \times 80 \mathrm{~kg})$, while the others were blast-frozen or slow-frozen (each $3 \times 80 \mathrm{~kg}$ ). Grapes were then processed with equipment suitable for the sizes of the batches being handled. The grapes for the fresh trial were immediately crushed/destemmed and pumped directly into the respective wine vats. A Gamma 50CE-RM (Toscana Enologica Mori, Italy) crusher/destemmer was used for the $500 \mathrm{~kg}$ batches, and an Enoitalia ENO-15 (Winery Supplies, Hallam, Australia) unit was used for the $80 \mathrm{~kg}$ batches. Grapes for slow freezing were placed into $\mathrm{a}-20^{\circ} \mathrm{C}$ cold room in sealed storage containers. Grapes for blast-freezing were transferred into lidded styrofoam boxes $(25 \mathrm{~kg})$ and transported to Swire Cold Storage (Mile End, South Australia), where the box lids were removed and the grapes frozen by blasting cold air $\left(-25^{\circ} \mathrm{C}\right)$ over them for 24 hours. Boxes were covered and then stored at $-20^{\circ} \mathrm{C}$ until they were ready to be used. Empirical observations revealed that blast-freezing froze all individual berries within 1-2 hours. Where grapes were frozen by slow freezing, berries at the center of the individual batches could take about 24 hours to freeze. Thawing of frozen/blast-frozen grapes before crushing occurred at $4^{\circ} \mathrm{C}$ to minimize any microbial spoilage.

\section{Fermentations}

All fermentations were carried out following the standard wine making practices used in the Hickinbotham Roseworthy Wine Science Laboratory (Waite Campus, The University of Adelaide, Australia). Briefly, standard additions of diammonium phosphate $(150 \mathrm{mg} / \mathrm{L})$ were made to the musts before inoculation with dried yeast (Maurivin ${ }^{\circledR}$ PDM, Mauri Yeast Australia, Sydney, Australia), reconstituted and added $(20 \mathrm{~g} / \mathrm{hL})$ following the manufacturer's instructions. Rotary fermentors (900 L capacity, A and G Industries, Victoria, Australia) were used to hold the $500 \mathrm{~kg}$ lots, and lidded 85 L flat-bottom, stainless-steel tanks (diameter $38 \mathrm{~cm}$, height $75 \mathrm{~cm}$ ) were used to hold the $80 \mathrm{~kg}$ lots. To avoid the rapid development of indigenous yeast during processing of thawed grapes, musts were inoculated at about $15^{\circ} \mathrm{C}$ rather than waiting for them to warm fully to $25^{\circ} \mathrm{C}$ (about 24 hours later). Subsequently, all fermentations were conducted at $25^{\circ} \mathrm{C} \pm 2{ }^{\circ} \mathrm{C}$. Samples were taken from each of the smaller fermentations after the cap was manually plunged every 12 hours (plunged 15 times). Rotary fermentors were turned three times clockwise and three times counterclockwise every 12 hours and sampled. Once below $1^{\circ}$ Baumé (Bé), the wines were pressed. The $500 \mathrm{~kg}$ batches were pressed using a Willmes VP1800 pneumatic press (two presses at 1 bar, two presses at 2 bar, with two crumples between presses), into $500 \mathrm{~L}$ holding tanks and kept at $20^{\circ} \mathrm{C}$. The $80 \mathrm{~kg}$ batches were pressed using a bladder press (Diemme 130 L Laboratory Press, JB Macmahon Pty Ltd, Forestville, Australia) operated using the following protocol; 0.2, 0.4, 0.6, 0.8 and 1 bar each held for five minutes with two crumples between presses. The wine was transferred to $85 \mathrm{~L}$ kegs and stored at $20^{\circ} \mathrm{C}$. Each wine was inoculated with Oenococcus oeni VP41 LAB (Lallemand, Underdale, Australia) at a rate of $1 \mathrm{~g} / \mathrm{hL}$ as per the manufacturer's instructions and underwent malolactic fermentation (residual malic acid concentration, $0.05 \mathrm{~g} / \mathrm{L}$ by enzymatic test kit, [Roche, Castle Hill, Australia]). Wines were racked off lees and prior to bottling and $\mathrm{SO}_{2}$ was adjusted to $75 \mathrm{mg} / \mathrm{L}$ total. The bottled wines were treated in the same manner by being stored at $15^{\circ} \mathrm{C}$ for at least one month prior to sensory evaluation.

\section{Chemical analysis by high-pressure liquid chromatography}

Organic acids (citric, malic, tartaric, succinic, lactic, and acetic), glycerol, acetaldehyde, and ethanol were determined in wine samples taken at the end of malolactic fermentation using a previously published method. ${ }^{5}$ Briefly, samples were analyzed using a Shimadzu LC-10 ATVP ion chromatograph system. Undiluted samples were automatically injected onto an Aminex H7X-8H column $(300 \times 7.8 \mathrm{~mm}$, BioRad). A mobile phase of aqueous $2.5 \mathrm{mM} \mathrm{H}_{2} \mathrm{SO}_{4}$ was used at a flow rate of $0.5 \mathrm{~mL} / \mathrm{min}$ and a column temperature of $60^{\circ} \mathrm{C}$. 
Organic acids were detected at a wavelength of $210 \mathrm{~nm}$ (Shimadzu SPD-10 AVP ultraviolet-visible detector) and other compounds detected using a Shimadzu RID-10A differential refractive index detector. All compounds were identified by their retention time and quantified by comparison with the peak area calculated for respective standards of known concentration.

\section{Color analysis by spectrophotometric methods}

Wine samples were analyzed for density, hue, $\mathrm{SO}_{2}$ resistant pigments, total anthocyanins, and total phenolics following a published method, ${ }^{6}$ and modified for use with 96-well ultraviolet transparent microtiter plates. Plates were read at various wavelengths using a Quant Microplate spectrophotometer (Bio-Tek Instruments). Samples $(50 \mu \mathrm{L})$ for total anthocyanin and total phenolic determinations were added to $1 \mathrm{M} \mathrm{HCl}(5 \mathrm{~mL})$ and incubated for a minimum of three hours at room temperature before aliquots $(300 \mu \mathrm{L})$ were transferred to 96 -well microtiter plates and read at $520 \mathrm{~nm}$ (total anthocyanins) and $280 \mathrm{~nm}$ (total phenolics). Density and hue were calculated from absorbance values of neat wine $(150 \mu \mathrm{L}$ aliquots in 96 -well microtiter plates) read at $420 \mathrm{~nm}$ and $520 \mathrm{~nm}$. SO resistant pigments were estimated by adding $15 \mu \mathrm{L} \mathrm{SO}$ solution $_{2}$ $(25 \% \mathrm{w} / \mathrm{v})$ to $1 \mathrm{~mL}$ of wine, and mixing and transferring $150 \mathrm{~mL}$ aliquots to 96 -well microtiter plates for measurement at $520 \mathrm{~nm}$.

\section{Color compound analysis by high-pressure liquid chromatography}

Anthocyanins in wine samples were separated and quantified by linear gradient elution as described previously ${ }^{7}$ using an Agilent 1100 high-pressure liquid chromatography system (Agilent Technologies) fitted with a Phenomonex Synergi Hydro-RP column $(150 \times 2 \mathrm{~mm})$. Solvent A consisted of $1 \%$ acetonitrile and $1.5 \%$ phosphoric acid in water. Solvent B was made up of $20 \%$ solvent A and $80 \%$ acetonitrile. Samples $(20 \mu \mathrm{L})$ were injected onto the column and eluted at $0.4 \mathrm{~mL} / \mathrm{min}$ using the following linear gradient: 0 minutes $(14.5 \% \mathrm{~B}), 18$ minutes $(27.5 \% \mathrm{~B})$, 20 minutes $(27.5 \% \mathrm{~B}), 21$ minutes $(50.5 \% \mathrm{~B}), 22$ minutes $(50.5 \%$ B), 26 minutes $(100 \%$ B), and 28 minutes $(100 \%$ B). A photodiode array detector $(520 \mathrm{~nm})$ was used to detect the anthocyanin compounds which were quantified as malvidin-3-glucoside equivalents. Individual compounds were identified from their elution time with respect to malvidin-3-glucoside.

\section{Sensory analysis}

Difference testing (duo-trio analysis) for color and aroma was firstly performed on the replicates of each treatment to determine variation, if any, within a treatment. Once this was established (see Results section) duo-trio analysis was then used to compare wines randomly from each treatment against each other. Wines $(30 \mathrm{~mL})$ were presented in random order against the reference in coded International Organization for Standardization standard tasting glasses and assessed at room temperature. Each participant was asked to pick the wine different to the reference based on color and aroma, and saw each wine at least twice over two sessions. Significant differences were calculated at $P<0.05$ using the critical number of correct responses for a duo-trio test. ${ }^{8}$

\section{Statistical analysis}

One-way analysis of variance with Tukey's multiple comparison post hoc test was performed using GraphPad Prism version 5.00 (GraphPad Software, San Diego, CA). A significance level of $P<0.05$ was used throughout.

\section{Results and discussion Comparison of small-scale and large-scale fermentations}

Whilst the $500 \mathrm{~kg}$ scale is widely accepted as representative of industrial pilot scale, ${ }^{9-13}$ only an anecdotal correlation exists between this and the laboratory $80 \mathrm{~kg}$ scale. Therefore there is a degree of uncertainty around the appropriateness of a small lot fermentation system for modeling larger ferments. However, knowing the degree of agreement between the two scales is valuable in interpreting findings from future trials conducted with these systems. To get a better understanding of the relationship between these two scales, Merlot grapes were used to compare fermentation profiles, major metabolites, and wine color profiles (spectrophotometric analysis and high-pressure liquid chromatography). Monitoring of the fermentation progress of the $500 \mathrm{~kg}$ and $80 \mathrm{~kg}$ fresh musts showed equivalent fermentation rates, with both fermenting to dryness after 163 hours (Figure 1). There was a high degree of reproducibility within triplicates of all treatments as indicated by the small associated errors. The fermentations of previously frozen grapes were completed in a similar time, albeit with a longer and equivalent lag (discussed below). Chemical analysis of the wines from fresh grapes only shows a significant difference for tartaric acid (Table 1). Although significant, this difference was relatively small (about $0.5 \mathrm{~g} / \mathrm{L}$ ) and would most likely have little effect on the final sensory quality of the research wine. 


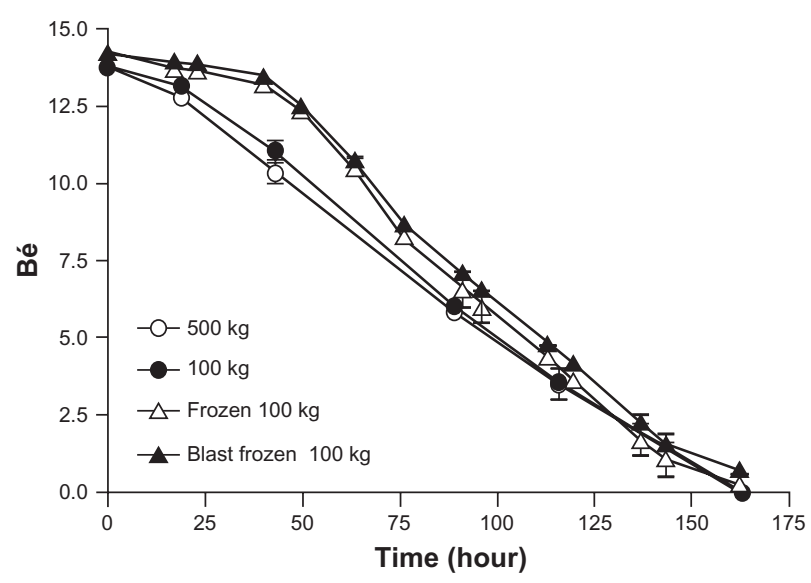

Figure I Fermentation progress of 500 and $80 \mathrm{~kg}$ fresh grape musts, and musts made from $80 \mathrm{~kg}$ each of frozen and blast-frozen grapes. Means and standard deviations represent triplicate fermentations.

Spectrophotometric color analysis of the wines produced from fresh grapes on the $80 \mathrm{~kg}$ and $500 \mathrm{~kg}$ scale, revealed significantly higher concentrations of total anthocyanins and total phenolics in the latter wines (Table 2). The cause of the color difference was further investigated by quantification of the major anthocyanins present in the wines, because spectrophotometric analysis does not give an accurate measure of the concentration of individual anthocyanins. A summary of compounds detected and confidently identified by high-pressure liquid chromatography in the wine samples with their concentrations (expressed as malvidin-3-glucoside equivalents) is shown in Table 3. In this analysis, no significant differences (Tukey's post test) were found in concentrations of individual anthocyanin compounds or total anthocyanin concentration. This would indicate that the extraction of anthocyanins using the rotary fermentor or manual plunging was similar and that the difference in color may be due to other parameters. As one possibility, the $\mathrm{pH}$ was 3.37 for the $500 \mathrm{~kg}$ wines and 3.45 for the $80 \mathrm{~kg}$ wines. The lower the $\mathrm{pH}$ of a wine the brighter the color of anthocyanins (brighter reds) and greater

Table I Chemical analysis of fresh 500 and $80 \mathrm{~kg}$, and frozen and blast-frozen $80 \mathrm{~kg}$ wine fermentation end samples

\begin{tabular}{lllll}
\hline Analyte (g/L) & $\begin{array}{l}\text { Fresh } \\
\mathbf{5 0 0} \mathbf{~ k g}\end{array}$ & $\begin{array}{l}\text { Fresh } \\
\mathbf{8 0} \mathbf{~ k g}\end{array}$ & $\begin{array}{l}\text { Frozen } \\
\mathbf{8 0} \mathbf{~ k g}\end{array}$ & $\begin{array}{l}\text { Blast-frozen } \\
\mathbf{8 0} \mathbf{~ k g}\end{array}$ \\
\hline Citric acid & 3.4 & 4.9 & 3.1 & 3.0 \\
Tartaric acid & $3.3^{\mathrm{a}-\mathrm{c}}$ & $2.8^{\mathrm{a}}$ & $2.4^{\mathrm{b}}$ & $2.6^{\mathrm{c}}$ \\
Succinic acid & 0.8 & 0.8 & 0.8 & 0.4 \\
Lactic acid & 5.5 & 5.6 & 4.5 & 4.3 \\
Glycerol & 14.5 & 14.0 & 13.7 & 13.9 \\
Acetic acid & 1.4 & 2.0 & 1.7 & 1.7 \\
Acetaldehyde & $0.05^{\mathrm{d}, \mathrm{e}}$ & $0.07^{\mathrm{f}, \mathrm{g}}$ & $0.09^{\mathrm{d}, \mathrm{f}}$ & $0.08^{\mathrm{e}, \mathrm{g}}$ \\
Ethanol & 90.0 & 88.8 & 93.7 & 95.2 \\
\hline
\end{tabular}

Notes: Values shown are the mean of triplicate fermentations. Only pairs of values within a given row identified by the same superscripted letters are significantly different $(P<0.05)$.
Table 2 Spectrophotometric color analyses of wines made by various treatments

\begin{tabular}{lllll}
\hline Parameter & F 500 kg & F 80 kg & Fr 80 kg & BF 80 kg \\
\hline Color density & $18.7^{\mathrm{a}}$ & 16.2 & 15.0 & $14.4^{\mathrm{a}}$ \\
Hue & $0.55^{\mathrm{b}, \mathrm{c}}$ & $0.56^{\mathrm{d}, \mathrm{e}}$ & $0.64^{\mathrm{b}, \mathrm{d}}$ & $0.63^{\mathrm{c}, \mathrm{e}}$ \\
$\mathrm{SO}_{2}$ resistant & $33.9^{2}$ & 42.8 & 33.9 & 34.4 \\
pigments (AU) & & & & \\
Total anthocyanins (AU) & $37.5^{\mathrm{f}}$ & $28 . \mathrm{I}^{\mathrm{f}}$ & 33.7 & 33.1 \\
Total phenolics (AU) & $14.8^{\mathrm{g}}$ & $10.0^{\mathrm{g}}$ & 12.9 & 12.6 \\
\hline
\end{tabular}

Notes: Values shown are the mean of triplicate fermentations. Only pairs of values within a given row identified by the same superscript letters are significantly different $(P<0.05)$.

Abbreviations: $\mathrm{Au}$, absorbance units; F, fresh; Fr, frozen; BF, blast-frozen.

the color intensity, with even small changes in $\mathrm{pH}$ affecting wine color. ${ }^{14}$ The fermentation data along with the chemical analysis of the wines made from $500 \mathrm{~kg}$ and $80 \mathrm{~kg}$ ferments shows good agreement between the laboratory scale $(80 \mathrm{~kg})$ and the pilot scale $(500 \mathrm{~kg})$, considered representative of commercial systems. This comparability of scale was also demonstrated in an earlier study ${ }^{3}$ where good agreement was seen between fermentations conducted at a smaller laboratory scale (20 kg and $50 \mathrm{~kg}$ ) compared with a larger scale $(300 \mathrm{~kg})$. Therefore, the small-scale winemaking practices employed in this study, and the winemaking outcomes of such small-scale trials could be extrapolated to larger scales with a high degree of confidence.

\section{Comparison of wines made from fresh, frozen, and blast-frozen grapes}

The protocol developed for small-scale fermentations which produced wines resembling those from larger-scale fermentations was used to make wines from grape bunches frozen conventionally or by blast-freezing. Application of such freezing treatments would likely be used to prolong research winemaking outside of the usual vintage period when access to winemaking facilities is more easily available, allowing an increased research output. Freezing would also allow for the same batches of grapes to be stored for later comparative trials.

Baumé readings of the fermenting musts made from frozen and blast-frozen grapes initially decreased at a slower rate compared with that seen for fermentations of the fresh grapes (Figure 1). After this time, fermentations progressed at similar rates with all four treatments, finishing at around 163-165 hours. The slower start seen in the frozen and blast-frozen fermentations is likely due to the time taken for these batches (inoculated at about $15^{\circ} \mathrm{C}$ ) to attain $25^{\circ} \mathrm{C}$. Again, the advanced seeding with yeast was an attempt to reduce development of indigenous yeast without resorting to the complication of adding higher concentrations of $\mathrm{SO}_{2}$. The initial $\mathrm{pH}$ was $0.7 \mathrm{pH}$ units higher in the musts from 
Table 3 Identification and quantification of anthocyanins by high-pressure liquid chromatography in fermentation end samples of fresh 500 and $80 \mathrm{~kg}$ musts, and musts made from frozen and blast-frozen grapes

\begin{tabular}{|c|c|c|c|c|}
\hline Analyte & $\begin{array}{l}F 500 \text { kg } \\
\text { (mg/L) }\end{array}$ & $\begin{array}{l}\text { F } 80 \text { kg } \\
\text { (mg/L) }\end{array}$ & $\begin{array}{l}\text { Fr } 80 \text { kg } \\
\text { (mg/L) }\end{array}$ & $\begin{array}{l}\text { BF } 80 \text { kg } \\
(\mathrm{mg} / \mathrm{L})\end{array}$ \\
\hline Delphinidin-3-glucoside & $19.2 \pm 1.4$ & $18.1 \pm 10.5$ & $9.8 \pm 2.7$ & $12.6 \pm 1.7$ \\
\hline Petunidin-3-glucoside & $18.9 \pm 2.1$ & $16.6 \pm 7.5$ & $12.6 \pm 3.6$ & $15.7 \pm 3.5$ \\
\hline Peonidin-3-glucoside & $9.1 \pm 1.2$ & $8.7 \pm 3.6$ & $6.3 \pm 1.8$ & $7.4 \pm 1.8$ \\
\hline Malvidin-3-glucoside & $112.5 \pm 6.8$ & $107.2 \pm 48.1$ & $96.0 \pm 27.2$ & $114.3 \pm 8.0$ \\
\hline Petunidin-acetyl-glucoside & $6.1 \pm 0.4$ & $6.2 \pm 2.7$ & $3.9 \pm 1.0$ & $5.6 \pm 0.2$ \\
\hline Peonidin-acetyl-glucoside & $4.7 \pm 0.2$ & $5.0 \pm 2.2$ & $4.0 \pm 1.2$ & $4.6 \pm 0.4$ \\
\hline Malvidin-acetyl-glucoside & $29.7 \pm 1.7$ & $28.3 \pm 13.2$ & $23.7 \pm 7.8$ & $29.3 \pm 1.9$ \\
\hline Total anthocyanin & $200.3 \pm 12.0$ & $190 \pm 87.8$ & $156.3 \pm 44.4$ & $189.4 \pm 17.3$ \\
\hline
\end{tabular}

Notes: Values represent the mean of triplicates \pm standard deviation. No significant differences were found between treatments for a given anthocyanin (Tukey's post test). Abbreviations: F, fresh; Fr, frozen; BF, blast-frozen.

frozen grapes than that from fresh grapes (even after addition of $2.5 \mathrm{~g} / \mathrm{L}$ tartaric acid). This is probably a result of potassium bitartrate precipitation as supported by analysis of the wines (Table 2). Nevertheless, it is unlikely to produce the observed effect, because yeast is likely to perform better at the higher $\mathrm{pH}$. A likely explanation that could account for the greater lag may be that the two batches of yeast used to ferment the fresh and frozen musts were in fact different.

Further comparison of the wines from fresh and frozen grapes revealed small but significant differences in the concentrations of tartaric acid and acetaldehyde (Table 2) which are unlikely to be differentiated by a sensory panel. These results indicate that wines made from grapes subjected to different freezing treatments generally had the same final chemical composition in terms of major organic acids, acetaldehyde, and alcohols compared with wines made from fresh grapes. Of the spectrophotometric color parameters determined, the most significant difference was found in hue (a measure of tint or shade). Wines made from both frozen treatments had higher hue values than those made from fresh grapes (Table 2), indicating that these wines were slightly darker. Color densities only differed between the fresh $500 \mathrm{~kg}$ and blast-frozen $80 \mathrm{~kg}$ wines.

Quantification of anthocyanins by high-pressure liquid chromatography for both frozen treatments revealed no significant differences in concentration of any compounds in any of the treatments (Table 3). Therefore, as discussed previously, the slight differences in color parameters measured by the spectrophotometric methods could not be attributed to differences in anthocyanin concentrations. Once again, the higher $\mathrm{pH}$ (approximately 3.6) of the wines made from either frozen treatment compared with wines made from fresh grapes (approximately 3.4) seems a likely cause for the observed spectrophotometric differences. A higher $\mathrm{pH}$ would make the wine from frozen grapes appear grayer with less color intensity, as was in fact observed (Table 2).
Despite the similarity between the four wines in terms of their chemical, color, and anthocyanin profiles, a sensory panel was used to ascertain whether aroma or color differences were perceivable via difference tests (duo-trio). Firstly, panel members were asked to identify if there were any differences within replicates of treatments. In each case, the number of correct responses was below that which would indicate a significant difference for both color and aroma (data not shown). One replicate wine from each treatment was then randomly selected and compared with a single replicate wine from each other treatment. The results obtained (Table 4) indicated that panelists were not able to distinguish between wines made from the $500 \mathrm{~kg}$ and $80 \mathrm{~kg}$ fermentations, thereby supporting the contention that at least with fresh grapes, the $80 \mathrm{~kg}$ scale was representative of the large pilot/small industrial scale. Comparison of findings for wines from frozen grapes revealed that significant sensory differences existed between all wines produced at the smaller scale. Thus, the choice of freezing treatment appears to impact significantly on the sensory properties of the finished wine. However, in seeking to identify a freezing method that allows wines to be produced on a smaller scale which closely resembles wines produced from fresh grapes on the $500 \mathrm{~kg}$ scale, the sensory panel results indicate blast-freezing to be preferable.

Table 4 Difference testing (duo-trio analysis) of wines derived from the various grape storage and fermentation treatments

\begin{tabular}{lllll}
\hline & F $500 ~ \mathbf{~ g ~}$ & F 80 kg & Fr 80 kg & BF 80 kg \\
\hline F $500 \mathrm{~kg}$ & & $26 / 44^{\text {nd }}$ & $35 / 44^{\text {sd }}$ & $27 / 44^{\text {nd }}$ \\
F 80 kg & & $29 / 40^{\text {sd }}$ & $26 / 40^{\text {sd }}$ \\
Fr 80 kg & & & $33 / 40^{\text {sd }}$ \\
BF 80 kg & & & \\
\hline
\end{tabular}

Notes: For $n=44$ and $n=40$, the minimum number of correct responses for a significant difference $(\alpha=0.05)$ is 28 and 26 , respectively. ${ }^{8}$ Value indicate the number of correct responses per total number of panelists.

Abbreviations: nd, no difference; sd, significant difference; F, fresh; Fr, frozen; BF, blast-frozen. 


\section{Conclusion}

This study extends on previous work conducted using frozen must, which demonstrated a high degree of similarity in the chemical and sensory properties of the resulting wines. ${ }^{3}$ Given the limitations of handling large volumes per se or frozen musts, the aim of this study was to determine the relevance of $80 \mathrm{~kg}$ fermentations to the pilot/small industrial scale $(500 \mathrm{~kg})$ as well as the optimal method of freezing whole grape bunches. Good correlation was found between $80 \mathrm{~kg}$ and $500 \mathrm{~kg}$ fermentations from fresh grapes. Similarly, small-scale fermentations using fresh, frozen, and blast-frozen red grapes showed marked similarity in terms of fermentation kinetics, metabolite profile, and color analysis. However, it was clear that freezing could introduce significant sensory differences. Whilst these were not defined via descriptive analysis, our previous study ${ }^{3}$ found such differences not to be based in negative traits but rather to stem from increased aroma freshness and red berry aromas.

The key conclusion of this study is that, under our conditions, grapes which have been blast-frozen before thawing and processing into wine produced wine that was most similar to that made from fresh grapes on the pilot/small industrial scale. The ability to extend vintage, reduce the volume, and therefore the demand and cost of grapes offered by this approach conveys significant advantages for research fermentations. Beyond this, recent developments suggest that cold and frozen storage of grapes may also have a role in commercial wine production, albeit for niche or small volume producers. ${ }^{15}$

The appropriateness of a given freezing method and fermentation volume will of course also be influenced by the objective of the fermentation trial. Thus, whilst small fermentations from frozen grapes are likely to be acceptable for comparisons of fermentation kinetics and gross metabolite production, some further evaluation might be warranted for studies with a focus on specifics of wine sensory or color properties.

\section{Acknowledgments}

This project was supported by Australia's grape growers and winemakers through their investment body the Grape and Wine Research and Development Corporation, with matching funds from the Australian Government (Project UA 06/01).

\section{Disclosure}

The authors report no conflicts of interest in this work.

\section{References}

1. Flora LF. Juice quality from whole muscadine grapes held in frozen storage. Am J Enol Vitic. 1976;27:84-87.

2. Spayd SE, Nagel CW, Hayrynen LD, Ahmedullah M. Effect of freezing fruit on the composition of musts and wines. Am J Enol Vitic. 1987;38: 243-245.

3. Schmid F, Li Y, Liebich B, Culbert J, Day C, Jiranek V. Evaluation of red wine made on a small scale utilizing frozen must. J Agric Food Chem. 2007;55:7156-7161.

4. Sacchi KL, Bisson LF, Adams DO. A review of the effect of winemaking techniques on phenolic extraction in red wines. Am J Enol Vitic. 2005; 56:197-206

5. Schneider A, Gerbi V, Redoglia M. A rapid HPLC method for separation and determination of major organic acids in grape musts and wines. Am J Enol Vitic. 1987;38:151-155.

6. Iland P, Grbin P, Grinbergs M, Schmidtke L, Soden A. Microbiological Analysis of Grapes and Wine: Techniques and Concepts. Campbelltown, SA: Patrick Iland Wine Promotions Pty Ltd; 2007.

7. Jeffery DW, Parker M, Smith PA. Flavonol composition of Australian red and white wines determined by high-performance liquid chromatography. Aust J Grape Wine Res. 2008;14:153-161.

8. Lawless HT, Heymann H. Sensory Evaluation of Food: Principles and Practices. New York, NY: Kluwer Academic/Plenum Publishers; 1999.

9. Bartowsky EJ, McCarthy JM, Siebert TE, et al. Malolactic fermentation: effect of strain on wine chemical composition and sensory properties. Proceedings of the 12th Australian Wine Industry Technical Conference, July 24-29, 2004, Melbourne, Victoria, Australia.

10. Birse M, Pollnitz AP, Kwiatkowski M, et al. Anthocyanins, anthocyaninderived pigments and the colour of red wine. Proceedings of the 12th Australian Wine Industry Technical Conference, July 24-29, 2004, Melbourne, Victoria, Australia.

11. Cozzolino D, Parker M, Dambergs RG, Herderich M, Gishen M. Chemometrics and visible-near infrared spectroscopic monitoring of red wine fermentation in a pilot scale. Biotechnol Bioeng. 2006;95: 1101-1107.

12. Dillon SJ, Bartowsky EJ, Lattey KA, et al. Effect of yeast on the colour, phenolics and sensory properties of a Shiraz wine. Proceedings of the 12th Australian Wine Industry Technical Conference, July 24-29, 2004, Melbourne, Victoria, Australia.

13. Eglinton J, Henschke PA. Winemaking properties of Saccharomyces bayanus - initial observations of the potential for red wine making. Aust N Z Grapgrwr Winemkr. 2003;473a:18-20.

14. Margalit Y. Concepts in Wine Technology. 1st ed. San Francisco, CA: Wine Appreciation Guild; 2004.

15. Jiranek V. Frozen grape research finds warm reception in the wine industry: A novel winemaking process and possible strategy for dealing with surplus grapes. Aust N Z Grapgrwr Winemkr. 2010;566:63-66.
International Journal of Wine Research

\section{Publish your work in this journal}

The International Journal of Wine Research is an international, peer-reviewed open-access, online journal focusing on all scientific aspects of wine, including: vine growing; wine elaboration; human interaction with wine; and health aspects of wine. The journal provides an open access platform for the reporting

\section{Dovepress}

of evidence based studies on these topics. The manuscript management system is completely online and includes a very quick and fair peer-review system, which is all easy to use. Visit http://www.dovepress.com/testimonials.php to read real quotes from some of our published authors. 